\title{
Improvement of TNO type trailing edge noise models
}

\author{
Fischer, Andreas; Bertagnolio, Franck; Aagaard Madsen , Helge
}

Published in:

Proceedings of 16th International Symposium on Transport Phenomena and Dynamics of Rotating Machinery

Publication date:

2016

Document Version

Peer reviewed version

Link back to DTU Orbit

Citation (APA):

Fischer, A., Bertagnolio, F., \& Aagaard Madsen , H. (2016). Improvement of TNO type trailing edge noise models. In Proceedings of 16th International Symposium on Transport Phenomena and Dynamics of Rotating Machinery

\section{General rights}

Copyright and moral rights for the publications made accessible in the public portal are retained by the authors and/or other copyright owners and it is a condition of accessing publications that users recognise and abide by the legal requirements associated with these rights.

- Users may download and print one copy of any publication from the public portal for the purpose of private study or research.

- You may not further distribute the material or use it for any profit-making activity or commercial gain

- You may freely distribute the URL identifying the publication in the public portal

If you believe that this document breaches copyright please contact us providing details, and we will remove access to the work immediately and investigate your claim. 


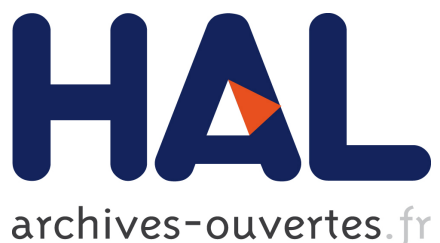

archives-ouvertes

\title{
Improvement of TNO type trailing edge noise models
}

\author{
Andreas Fischer, Franck Bertagnolio, Helge Madsen
}

\section{To cite this version:}

Andreas Fischer, Franck Bertagnolio, Helge Madsen. Improvement of TNO type trailing edge noise models. 16th International Symposium on Transport Phenomena and Dynamics of Rotating Machinery, Apr 2016, Honolulu, United States. hal-01891316

\section{HAL Id: hal-01891316 \\ https://hal.archives-ouvertes.fr/hal-01891316}

Submitted on 9 Oct 2018

HAL is a multi-disciplinary open access archive for the deposit and dissemination of scientific research documents, whether they are published or not. The documents may come from teaching and research institutions in France or abroad, or from public or private research centers.
L'archive ouverte pluridisciplinaire HAL, est destinée au dépôt et à la diffusion de documents scientifiques de niveau recherche, publiés ou non, émanant des établissements d'enseignement et de recherche français ou étrangers, des laboratoires publics ou privés. 


\title{
Improvement of TNO type trailing edge noise models
}

\author{
Andreas Fischer ${ }^{1 *}$, Franck Bertagnolio ${ }^{1}$, Helge Aa. Madsen ${ }^{1}$
}

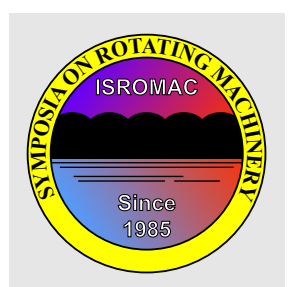

ISROMAC 2016

International

Symposium on Transport

Phenomena and Dynamics of

Rotating Machinery

Hawaii, Honolulu

April 10-15, 2016

\section{Abstract}

The paper describes an improvement of the so-called TNO model to predict the noise emission from aerofoil sections due to the interaction of the boundary layer turbulence with the trailing edge. The surface pressure field close to the trailing edge acts as source of sound in the TNO model. It is computed by solving a Poisson equation which includes flow turbulence cross correlation terms. Previously published TNO type models used the assumption of Blake to simplify the Poisson equation. This paper shows that the simplification should not be used. We present a new model which fully models the turbulence cross correlation terms. The predictions of the new model are in better agreement with measurements of the surface pressure and far field sound spectra. The computational cost of the new model is only slightly higher than the one of the TNO model, because we derived an analytical solution for the turbulence cross correlation terms.

\section{Keywords}

trailing edge noise - TNO model

\author{
${ }^{1}$ DTU Wind Energy, Technical University of Denmark, Roskilde, Denmark \\ *Corresponding author: asfi@dtu.dk
}

\section{INTRODUCTION}

The noise emission of the blades of rotating machinery due to the interaction of the boundary layer turbulence with the trailing edge, so called trailing edge (TE) noise, plays an important role. For fans operating with a subsonic open rotor TE noise dictates the minimum achievable noise emission [1]. Oerlemans et al. [2] showed that TE noise is the dominant noise mechanism of modern wind turbines during most of the operation conditions. Hence, the capability to fast and accurately model TE noise is the key to reduce noise from rotating machinery.

Parchen [3] at the TNO Institute of Applied Physics in the Netherlands developed a computationally fast TE noise model which is being used by many research institutions. We call the models based on this approach TNO type model in the following. The original TNO model was applied to predict wind turbine noise by Moriarty et al. [4]. Later the TNO type models were studied in detail by research groups at the University of Stuttgart $[5,6]$, the Technical University of Denmark [7, 8] and in combined effort [9]. Most recently Stalnov [10] at the University of Southampton also started to investigate this type of model. Also worth mentioning are the investigations of trailing edge noise by Remmler et al. [11] and Rozenberg et al. [12]. However, these approaches are different in the way to compute the surface pressures. Remmler et al. [11] uses large eddy simulations and Rozenberg et al. [12] uses experimental data.

The surface pressure field at the TE of the aerofoil is the source of the emitted sound. The TNO type models use the analytical solution of Kraichnan [13] together with a sim- plification proposed by Blake [14] to compute the surface pressure field. To close the model the velocity field in the boundary layer has to be modelled. The greatest challenge was modelling the spectrum and vertical length scale of the vertical velocity fluctuations. By applying several empirical corrections it was possible to achieve a good agreement between measurements and predictions at moderate angles of attack $[6,10]$. But the response of the model to a change in angle of attack was different than indicated by the measurements. The far field sound was underpredicted at high angles of attack. The response to the angle of attack change was improved by Bertagnolio et al. [7] with an empirical tuning related to a non-dimensional pressure gradient in the boundary layer flow which increases proportional to the angle of attack. However, only in the high frequency range the model gave good results. In the low frequency range the measurements were overestimated.

In this work we revised the way to compute the surface pressure field. The starting point for the development of the new model was Kraichnan's analytical solution, but we avoided to use Blake's assumption. Instead the cross spectral function of the vertical velocity was fully modelled. The new model gives significantly better results when comparing surface pressure and far field sound predictions with measurements.

The basic theory of trailing edge noise modelling is outlined in the first part of the paper. Then we describe the development of the new trailing edge noise model. The new model is validated by a comparison of predicted and measured surface pressure one point spectra and far field sound spectra. The most important findings are summarised in a short discussion at the end of the paper. 


\section{TRAILING EDGE NOISE MODEL}

The TNO type analytical TE noise models use a two step approach. First the surface pressure spectrum is related to parameters of the boundary layer flow. The boundary layer flow parameters can be computed with CFD RANS calculations or other computational methods like XFOIL [15]. The analytical expression for the surface pressure spectrum was first derived by Kraichnan [13] and further developed by Blake [14].

As second step the convecting surface pressure spectrum upstream of the TE is related to the radiated far field sound. There are two independent approaches for this task. We use the generalised theory by Howe [16] which was initially developed by Chase [17] and Chandiramani [18]. Alternatively there is the theory of Amiet [19] which has recently been refined by Roger and Moreau [1]. A detailed analysis of the difference of the two theories is found in [8].

\subsection{Far Field Sound}

Howe [16] assumes a infinite half-plane configuration to represent the aerofoil as depicted in figure 1. The relation

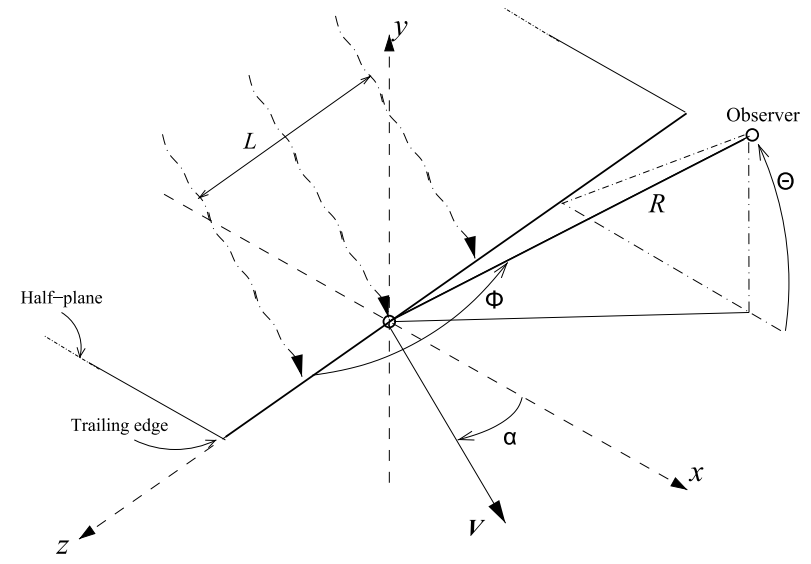

Figure 1. Half plane configuration to represent aerofoil geometry. (Figure taken from [20])

between the far field sound and the surface pressure given by Howe [16] for a flow leaving the trailing edge perpendicularly $\left(\alpha=0^{\circ}\right)$ is

$$
\begin{aligned}
& S(\omega)=\frac{L}{2 \pi R^{2}} D \\
& \quad \int_{-\infty}^{\infty} \frac{\omega}{c_{0}\left|k_{1}\right|} \frac{\Pi\left(k_{1},\left(\omega / c_{0}\right) \cos \Phi, \omega\right)}{\left(1-\frac{\omega}{c_{0}\left|k_{1}\right|} \sin \Phi \cos \Theta\right)^{2}\left(1-\frac{\omega}{c_{0}\left|k_{1}\right|} \sin \Phi\right)} d k_{1}
\end{aligned}
$$

with the directivity factor

$$
D=\frac{\sin \Phi \sin ^{2}(\Theta / 2)}{\left(1+M_{0} \sin \Phi \cos \Theta\right)^{2}\left(1-M_{W} \sin \Phi \cos \Theta\right)^{2}} .
$$

$\Pi\left(\mathrm{k}_{1}, \mathrm{k}_{3}, \omega\right)$ is the frequency wave number spectrum of the convecting surface pressure.

For most TNO type models equation 1 was studied for an observer located in the centre of the wetted span and perpendicular above the TE $\left(\Phi=90^{\circ}, \Theta=90^{\circ}\right)$. It simplifies then to [21]

$$
S(\omega)=\frac{L}{4 \pi R^{2}} \int_{-\infty}^{\infty} \frac{\omega}{c_{0}\left|k_{1}\right|} \frac{\Pi\left(k_{1}, 0, \omega\right)}{1-\frac{\omega}{c_{0}\left|k_{1}\right|}} d k_{1} .
$$

Note that the factor including the convective Mach number $1-\frac{\omega}{c_{0}\left|k_{1}\right|}$ is most often neglected in wind energy applications where the free stream Mach number is low. Assuming frozen turbulence the factor $\frac{\omega}{c_{0}\left|k_{1}\right|}$ simplifies to $\frac{U_{c}}{c_{0}}$. $\mathrm{U}_{c}$ is the eddy convection velocity. It is parallel to the mean flow direction. This factor is slightly lower than the free stream Mach number.

\subsection{Convecting Surface Pressure}

Kraichnan [13] solves the poisson equation to calculate the frequency wave number spectrum of the surface pressure of an incompressible boundary layer flow on the plane y $=0$, figure 2 . He introduces the Fourier transform in the

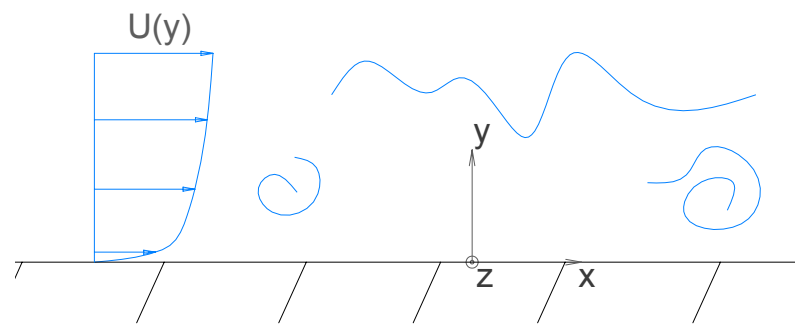

Figure 2. The configuration for Kraichnan's surface pressure model.

streamwise direction $\mathrm{x}$ and the in-plane normal component $\mathrm{z}$. Due to the inhomogeneity the Fourier transform is omitted in the vertical direction y. Kraichnan's result for the surface pressure spectrum is

$$
\begin{gathered}
\Pi=4 \rho_{0}^{2} \iint_{0}^{\infty}\left(k_{1} / \kappa\right)^{2} \frac{d U}{d y}\left(y^{\prime}\right) \frac{d U}{d y}(y) \\
\sqrt{v^{2}(y) v^{2}\left(y^{\prime}\right)} \frac{\left\langle\hat{v}^{*}\left(k_{1}, k_{3}, y^{\prime}, \omega\right) \hat{v}\left(k_{1}, k_{3}, y, \omega\right)\right\rangle}{\sqrt{v^{2}(y) v^{2}\left(y^{\prime}\right)}} e^{-\kappa\left(y+y^{\prime}\right)} d y d y^{\prime} .
\end{gathered}
$$

$\frac{\left\langle\hat{v}^{*}\left(k_{1}, k_{3}, y^{\prime}, \omega\right) \hat{v}\left(k_{1}, k_{3}, y, \omega\right)\right\rangle}{\sqrt{v^{2}(y) v^{2}\left(y^{\prime}\right)}}$ is the normalised frequency wave number cross spectrum of the vertical velocity for vertical separation $r_{2}=y-y^{\prime}$. The challenge in using equation 4 lies in the modelling of this function. Note that in Kraichnan's results the turbulence-turbulence interaction source terms were neglected. This assumptions needs to be checked when dealing with low Reynolds number flows.

Blake [14] separated $\frac{\left\langle\hat{v}^{*}\left(k_{1}, k_{3}, y^{\prime}, \omega\right) \hat{v}\left(k_{1}, k_{3}, y, \omega\right)\right\rangle}{\sqrt{v^{2}(y) v^{2}\left(y^{\prime}\right)}}$ into

$$
\begin{aligned}
& \frac{\left\langle\hat{v}^{*}\left(k_{1}, k_{3}, y^{\prime}, \omega\right) \hat{v}\left(k_{1}, k_{3}, y, \omega\right)\right\rangle}{\sqrt{v^{2}(y) v^{2}\left(y^{\prime}\right)}}= \\
& 2 L_{2}^{22} \delta\left(y-y^{\prime}\right) \phi_{22}\left(k_{1}, k_{3}, y\right) \phi_{m}\left(\omega-U_{c} k_{1}\right) .
\end{aligned}
$$


The frequency dependence was separated into the so called moving axis spectrum $\phi_{m}$. The eddy convection velocity $\mathrm{U}_{c}$ is in the order of the local mean velocity. Hence, it can be written

$$
U_{c}(y)=c U(y)
$$

Parchen [3] suggests a value of $c=0.7$ when comparing the mean convection velocity of the boundary layer to the free stream velocity. The mean convection velocity was an average over time and space (i.e. the extend of the boundary layer). However, in our model the local convection velocity is involved as function of the vertical coordinate $y$. It is an average over time, but not over space. It was assumed that an eddy convects with the local flow velocity, $\mathrm{c}=1$, in order to be consistent with the assumptions made for the derivation of the far field sound by Howe [16] and the assumptions we make to convert a measured frequency spectrum into a one point wave number spectrum.

The cross correlation was simplified to a function of the vertical length scale and a delta function. This is valid if the correlation length scale is much smaller than the boundary layer thickness, $\mathrm{L}_{2}^{22}<<\delta$. Mathematically it means that $\frac{d U}{d y}, \mathrm{v}^{2}$ and $\mathrm{e}^{-\kappa y}$ are assumed to be constant within the layer $y-y$. Note that the factor 2 in front of the length scale $L_{2}^{22}$ was introduced based on the argumentation of Bertagnolio et al. [7]. Performing the integration over y' and making use of the delta function in eq. 5 , equation 4 becomes

$$
\Pi=4 \rho_{0}^{2} \int_{0}^{\infty} \frac{k_{1}^{2}}{\kappa^{2}}\left(\frac{d U}{d y}\right)^{2} v^{2} 2 L_{2}^{22} \phi_{22} \phi_{m} e^{-2 \kappa y} d y .
$$

The assumptions to derive eq. 7 imply some severe simplifications which cannot be physically justified.

\subsection{Turbulence Modelling}

To close the model which is constituted by eq. 7 the length scale $L_{2}^{22}$ and the auto spectrum of the vertical velocity $\phi_{22}$ as function of the streamwise and lateral wave number, $k_{1}$ and $k_{3}$ need to be calculated. Parchen [3] develops these expression based on the classical von Karman spectrum [22]. The energy spectrum for isotropic turbulence introduced by von Karman [22] reads

$$
E(k)=\alpha \epsilon^{2 / 3} \Lambda^{5 / 3} \frac{(\Lambda k)^{4}}{\left(1+(\Lambda k)^{2}\right)^{17 / 6}}
$$

with the norm of the wave number

$$
k^{2}=k_{1}^{2}+k_{2}^{2}+k_{3}^{2} .
$$

The dissipation can be approximated as

$$
\epsilon \propto \frac{\left(u_{0}^{2}\right)^{3 / 2}}{\Lambda}
$$

if the energy containing eddies break up at a time scale equal to their turn over time [23]. $\mathrm{u}_{0}^{2}$ is the variance of a velocity component for isotropic turbulence. Its relation to the turbulent kinetic energy is

$$
u_{0}^{2}=\frac{2}{3} k_{t}
$$

This assumption makes it possible to relate the parameters of equation 8 to the output of the $\mathrm{k}, \epsilon$-model used in CFD RANS computations.

With equation 10 the energy spectrum, equation 8 , reads

$$
E(k)=\bar{\alpha} u_{0}^{2} \Lambda \frac{(\Lambda k)^{4}}{\left(1+(\Lambda k)^{2}\right)^{17 / 6}}
$$

where the constant $\bar{\alpha}$ should be chosen as

$$
\bar{\alpha}=\frac{55}{9 \sqrt{\pi}} \frac{\Gamma(5 / 6)}{\Gamma(1 / 3)}
$$

to ensure that

$$
k_{t}=\int_{0}^{\infty} E(k) d k .
$$

To relate the length scale of the von Karman spectrum $\Lambda$ to the turbulent kinetic energy $k_{t}$ and the dissipation $\epsilon$ computed with CFD RANS we use an approach described by Lutz et al. [5]. Comparing the asymptotic behaviour of equations 8 and 12 for the wave number $k$ towards infinity one finds

$$
\Lambda=\alpha_{\Lambda} \frac{k_{t}^{3 / 2}}{\epsilon}
$$

with

$$
\alpha_{\Lambda}=\left(\frac{2 \bar{\alpha}}{3 \alpha}\right)^{3 / 2} .
$$

Lutz et al. [5] assume a value for $\alpha$ of 1.5 by referring to measurements by Lysak and Brungart [24]. Hence, equation 16 yields $\alpha_{\Lambda}=0.5188$. Mann [25] proposes a slightly different value for $\alpha$ of 1.7. With this value, eq. 16 yields $\alpha_{\Lambda}=0.43$. A new and not yet published study based on the velocity measurements in the boundary layer of a NACA0015 aerofoil presented in [23] motivated to use Mann's value.

The normalised von Karman spectrum of the vertical velocity fluctuations reads

$$
\Phi_{22}=\frac{55}{36 \pi^{3 / 2}} \frac{\Gamma(5 / 6)}{\Gamma(1 / 3)} \Lambda^{3} \frac{(\Lambda \kappa)^{2}}{\left[1+(\Lambda k)^{2}\right]^{17 / 6}}
$$

with the norm of the wavenumber vector spanning the planes parallel to the wall,

$$
\kappa^{2}=k_{1}^{2}+k_{3}^{2} .
$$

Integrating eq. 17 over the vertical wave number $k_{2}$ yields the auto spectrum of the vertical velocity as function of 
the streamwise and lateral wave number used in Parchen's original model. It reads

$$
\phi_{22}=\frac{4}{9 \pi} \Lambda^{2} \frac{(\Lambda \kappa)^{2}}{[1+(\Lambda \kappa)]^{7 / 3}} .
$$

Parchen uses the vertical integral length scale $\Lambda_{2}^{22}$ to model the correlation length scale $L_{2}^{22}$. The integral length scale can be computed from the length scale $\Lambda$ by

$$
\Lambda_{2}^{22}=\frac{\sqrt{\pi} \Gamma(5 / 6)}{\Gamma(1 / 3)} \Lambda
$$

The variance of the vertical velocity fluctuations is computed as $\mathrm{v}^{2}=\frac{4}{9} \mathrm{k}_{t}$.

Bertagnolio et al. [7] introduced anisotropy parameters $\beta_{1}$, $\beta_{2}$ and $\beta_{3}$ as proposed by Panton and Linebarger [26] to the wave number spectrum. The anisotropic auto spectrum of the vertical velocity as function of the streamwise and lateral wave number reads

$$
\phi_{22}^{a}=\int_{-\infty}^{\infty} \Phi_{22}^{a} d k_{2}=\frac{4}{9 \pi} \Lambda^{2} \beta_{1} \beta_{3} \frac{\eta_{1}^{2}+\eta_{3}^{2}}{\left[1+\eta_{1}^{2}+\eta_{3}^{2}\right]^{7 / 3}}
$$

with

$$
\begin{aligned}
& \eta_{1}=\beta_{1} \Lambda k_{1} \\
& \eta_{2}=\beta_{2} \Lambda k_{2} \\
& \eta_{3}=\beta_{3} \Lambda k_{3} .
\end{aligned}
$$

In the model developed by Bertagnolio et al. the anisotropy parameters $\beta_{1}, \beta_{2}$ and $\beta_{3}$ were dependent on the local pressure gradient. We used the fixed values $\beta_{1}=1, \beta_{2}=$ 0.74 and $\beta_{3}=0.9$. This choice was based the yet unpublished study of the measurements of the boundary layer velocity spectra on a NACA0015 aerofoil presented in [23]. The vertical correlation length scale as proposed by Bertagnolio et al. [7] is frequency dependent. It reads

$$
L_{2}^{22}=\frac{\Gamma(1 / 3) \sqrt{\pi}}{3 \Gamma(5 / 6)} \Lambda \beta_{2} \frac{3+11 \eta_{c}^{2}}{3+8 \eta_{c}^{2}} \frac{1}{\sqrt{1+\eta_{c}^{2}}}
$$

with

$$
\eta_{c}=\beta_{1} \Lambda \frac{\omega}{U_{c}} .
$$

\subsection{Development of a new Model}

To develop an improved model we start with Kraichnan's solution [13] for the surface pressure, eq. 4, but make a different assumption than Blake [14] to model the cross spectrum of the vertical velocity. Instead of Blake's assumption, eq. 5 , we model the vertical velocity cross spectrum as

$$
\begin{aligned}
& \frac{\left\langle\hat{v}^{*}\left(k_{1}, k_{3}, y^{\prime}, \omega\right) \hat{v}\left(k_{1}, k_{3}, y, \omega\right)\right\rangle}{\sqrt{v^{2}(y) v^{2}\left(y^{\prime}\right)}} \\
= & \gamma_{22}^{a}\left(k_{1}, k_{3}, y, y^{\prime}\right) \phi_{22}^{a}\left(k_{1}, k_{3}, y\right) \phi_{m}\left(\omega-U_{c} k_{1}\right) .
\end{aligned}
$$

Hence, the same assumption is made when separating the frequency dependence into the moving axis spectrum. But the vertical cross correlation function is analytically exact. Introducing eq. 27 into Kraichnan's eq. 4 yields

$$
\begin{array}{r}
\Pi=4 \rho_{0}^{2} \int_{y=0}^{\infty} \int_{y^{\prime}=0}^{\infty}\left(k_{1} / \kappa\right)^{2} \frac{d U}{d y}\left(y^{\prime}\right) \sqrt{v^{2}\left(y^{\prime}\right)} \gamma_{22}^{a}\left(k_{1}, k_{3}, y, y^{\prime}\right) \\
\phi_{m}\left(\omega-U_{c} k_{1}\right) e^{-\kappa y^{\prime}} d y^{\prime} \frac{d U}{d y}(y) \sqrt{\left.v^{2}(y)\right)} \phi_{22}^{a}\left(k_{1}, k_{3}, y\right) e^{-\kappa y} d y .
\end{array}
$$

The cross correlation function of the planar wave numbers $\mathrm{k}_{1}$ and $\mathrm{k}_{3}$ and the vertical separation $\mathrm{y}-\mathrm{y}$ ' can be evaluated with the integral

$\int_{k_{2}=-\infty}^{\infty} e^{-i k_{2}\left(y-y^{\prime}\right)} \Phi_{22}^{a}\left(k_{1}, k_{2}, k_{3}\right) d k_{2}=\gamma_{22}^{a}\left(k_{1}, k_{3}, y, y^{\prime}\right) \phi_{22}^{a}\left(k_{1}, k_{3}\right)$.

It yields

$$
\gamma_{22}^{a}\left(k_{1}, k_{3}, y, y^{\prime}\right)=\frac{9}{4} \frac{1}{2^{4 / 3} \Gamma(1 / 3)} \zeta^{7 / 3} \mathbb{K}_{-7 / 3}(\zeta)
$$

where $\mathbb{K}_{v}(z)$ is the modified Bessel function of second kind and $\zeta$ is defined as

$$
\zeta=\frac{\left|y-y^{\prime}\right|}{\beta_{2} \Lambda} \sqrt{1+\eta_{1}^{2}+\eta_{3}^{2}} .
$$

Note that we have introduced the anisotropy parameters $\beta_{1}$, $\beta_{2}$ and $\beta_{3}$ as proposed by Bertagnolio et al. [7].

Some more modelling is necessary for the length scale $\Lambda(\mathrm{y})$ and the convection velocity $U_{c}$ as they depend on y and y' in the new model. The length scale $\Lambda\left(y, y^{\prime}\right)$ is represented by the geometric mean

$$
\Lambda\left(y, y^{\prime}\right)=\sqrt{\Lambda(y) \Lambda\left(y^{\prime}\right)} .
$$

This approach was motivated by the study presented in [8]. The convection velocity $U_{c}\left(\mathrm{y}, \mathrm{y}^{\prime}\right)$ is modelled with the arithmetic mean

$$
U_{c}\left(y, y^{\prime}\right)=\frac{U_{c}(y)+U_{c}\left(y^{\prime}\right)}{2}
$$

following the argumentation of Mann [25]. A more detailed analysis of these quantities was out of scope.

\section{EVALUATION OF THE TRAILING EDGE NOISE MODELS}

In this section the different TE noise models are evaluated by comparison to measurements. We call the original model by Parchen [3] MO and the model with the extensions of Bertagnolio et al. [7] MB. Note that these models are different to their published version, because we used 
different input parameters as described above. The new model is called M2I. We used the BANC III data base [27] as reference measurements. It was created for the purpose of evaluating TNO type TE noise models. First, the measurement data base is briefly described. Then we compare surface pressure and far field sound predictions to the measurements.

\subsection{The BANC III Database for Validation}

The BANC III database [27] contains far field sound pressure spectra in $1 / 3$ octave bands obtained from measurements performed in the laminar wind tunnel of the Univeristy of Stuttgart (IAG LWT), in the acoustic wind tunnel of the German Aerospace Centre in Braunschweig (DLR AWB) and in the aeroacoustic flow facility of the University of Florida (UFL UFAFF). The spectra were referenced to an observer position at $1 \mathrm{~m}$ distance and the elevation angles $\Phi=90^{\circ}$ and $\Theta=90^{\circ}$. A short list of the test conditions is provided in table 1 and details are found in [27]. In all

\begin{tabular}{|c|c|c|c|c|}
\hline Case $[-]$ & aerofoil & $\mathrm{Re} / 10^{6}$ & $\alpha[\mathrm{deg}]$ & $\mathrm{U}_{\infty}[\mathrm{m} / \mathrm{s}]$ \\
\hline 1 & NACA0012 & 1.5 & 0 & 56.0 \\
2 & NACA0012 & 1.5 & 4 & 54.8 \\
3 & NACA0012 & 1.5 & 6 & 53.0 \\
4 & NACA0012 & 1.0 & 0 & 37.7 \\
5 & DU96-W-180 & 1.13 & 4 & 60.0 \\
\hline
\end{tabular}

Table 1. BANC III test cases [27].

test cases transition of the boundary layer was enforced to occur close to the leading edge by mounting trip tape on the pressure and suction side. The uncertainty of the far field sound pressure measurements was estimated to be $\pm 3 \mathrm{~dB}$. The cases with NACA0012 aerofoil (cases 1 to 4 ) also contain measurements of the surface pressure spectra at chord position $\mathrm{x} / \mathrm{c}=0.99$ on the suction and pressure side and measurements of the velocity profiles, Reynolds stresses, turbulent kinetic energy and dissipation in the near wake at $\mathrm{x} / \mathrm{c}=1.0038$ on the suction side. Those measurements were conducted in the IAG LWT. Case 5 does not include these extra measurements.

CFD RANS computations providing the input to the TE noise models were performed with the in house flow solver EllipSys 2D [28, 29, 30]. The results of the CFD computations were compared to measurements of the relevant boundary layer quantities on the suction side at the position $\mathrm{x} / \mathrm{c}=0.99$ in figure 3,4 and 5. There is a good agreement between measurement and computation for the velocity and the dissipation. The turbulent kinetic energy is underestimated at high angles of attack. The boundary layer quantities were not validated on the pressure side.

\subsection{Evaluation of the Surface Pressure Predic- tions}

The surface pressure frequency spectrum is calculated by integrating the frequency wave number spectrum $\Pi$, eq. 4 ,

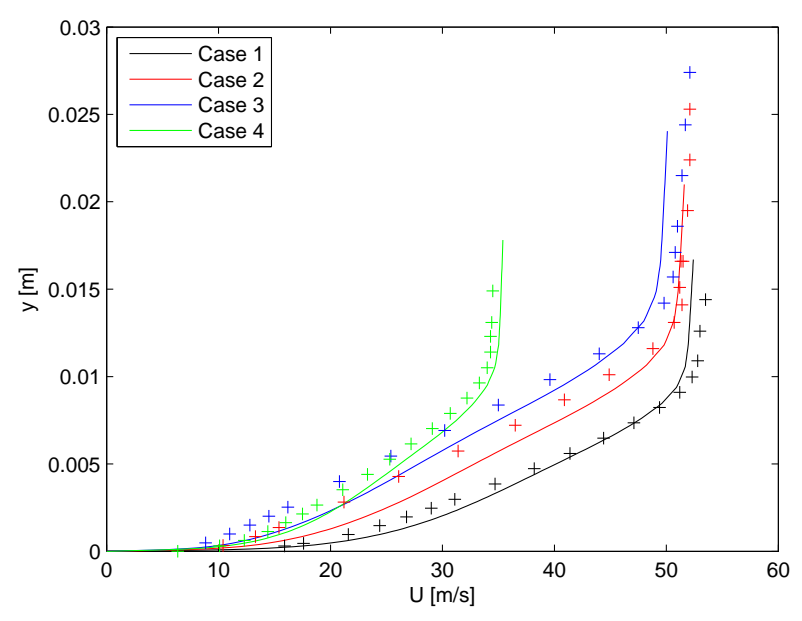

Figure 3. Computed velocity profile compared to the measurements of the BANC III data base.

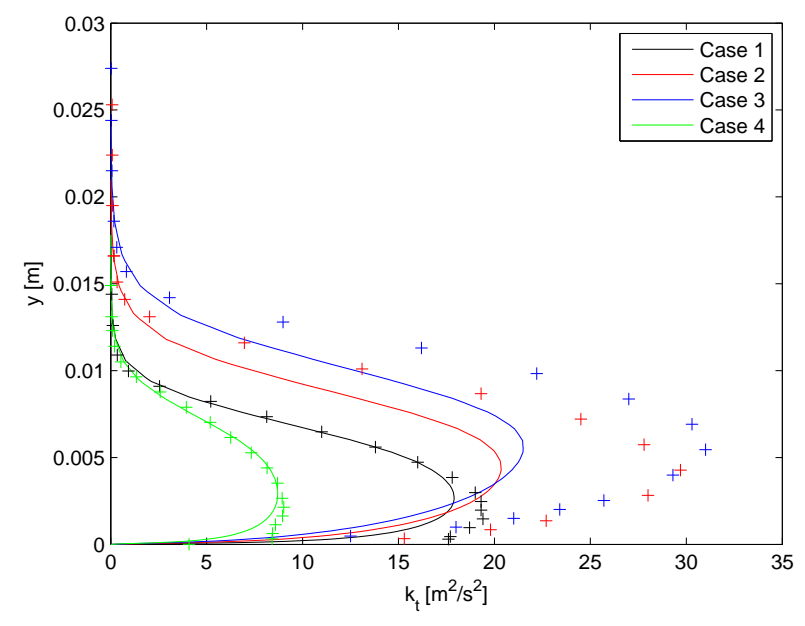

Figure 4. Computed turbulent kinetic energy compared to the measurements of the BANC III data base.

over the 2 dimensional wave number space $\mathrm{k}_{1}-\mathrm{k}_{3}$

$$
S_{p p}(\omega)=\int_{-\infty}^{\infty} \int^{\infty} \Pi\left(k_{1}, k_{3}, \omega\right) d k_{1} d k_{3} .
$$

Figures 6, 7, 8 and 9 show the comparison of the predicted surface pressure with the measurements of the BANC III database, case 1 to 4 . The original isotropic model MO and the modified model MB give very similar results in terms of peak level and spectral shape. The peak level of the BANC III measurements is underestimated by up to $6 \mathrm{~dB}$ in all cases. The spectral shape is not predicted correctly. The largest differences between prediction and measurement are observed in the low frequency range.

The predictions with the M2I model are in very good agreement with the measurements on the suction side for all the 4 cases. Hence, the failure of the MO and MB model 


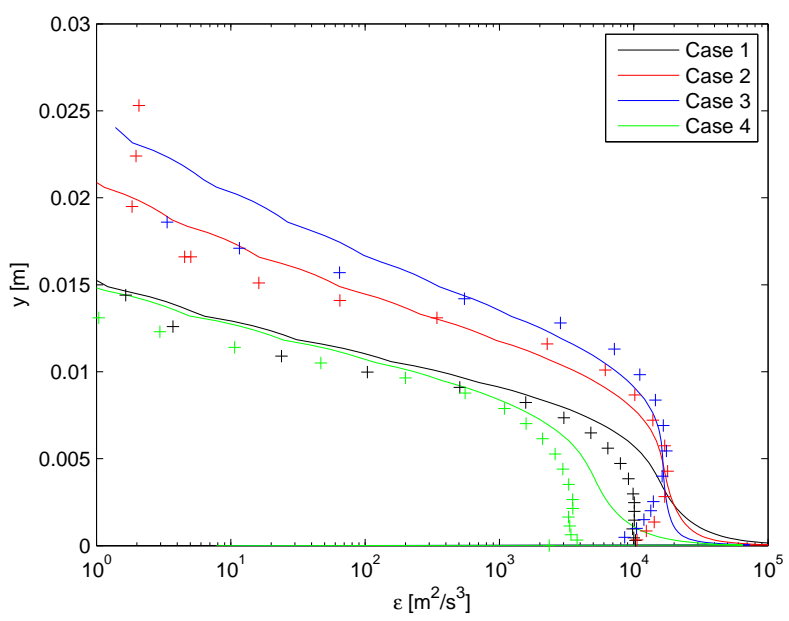

Figure 5. Computed dissipation compared to the measurements of the BANC III data base.

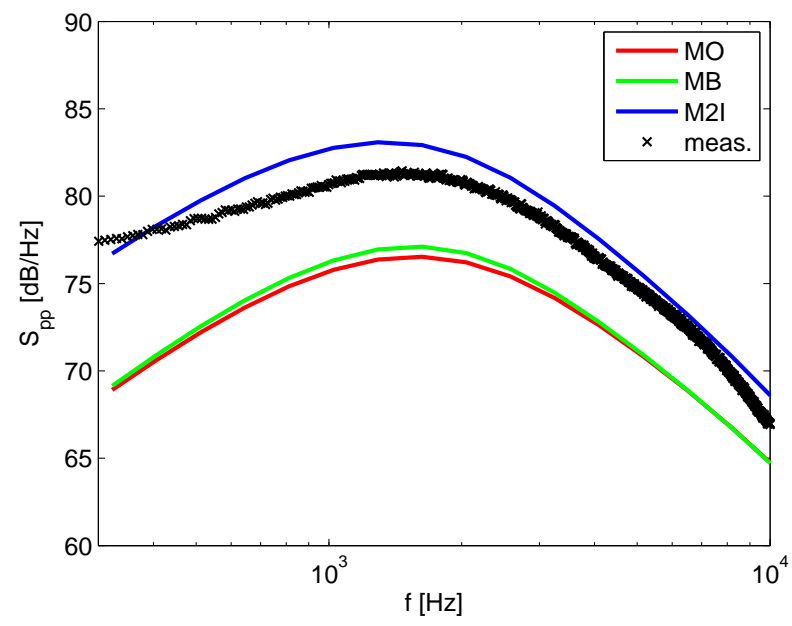

Figure 6. Surface pressure computations compared to the BANC III measurements, case 1.

must be due to the Blake assumption, eq. 5. The small differences between the predictions with the M2I model and the measurements on the suction side might originate from a erroneous spectral modelling of the vertical velocity. The spectral energy of the measured surface pressure spectrum is more evenly distributed over frequency than the predicted one. Using the Mann model to describe the wave number spectrum of the vertical velocity might improve the prediction of the surface pressure spectrum. It was not attempted due to the high computational costs and the complexity of such a model.

The M2I model overpredicts the surface pressure on the pressure side by about $3 \mathrm{~dB}$ for the cases 2 and 3 with AOAs $\alpha=4^{\circ}$ and $\alpha=6^{\circ}$. The error might origin from the turbulence modelling on the pressure side. The CFD input for the model, velocity profile, turbulent kinetic energy and dissipation, were validated with measurements on the

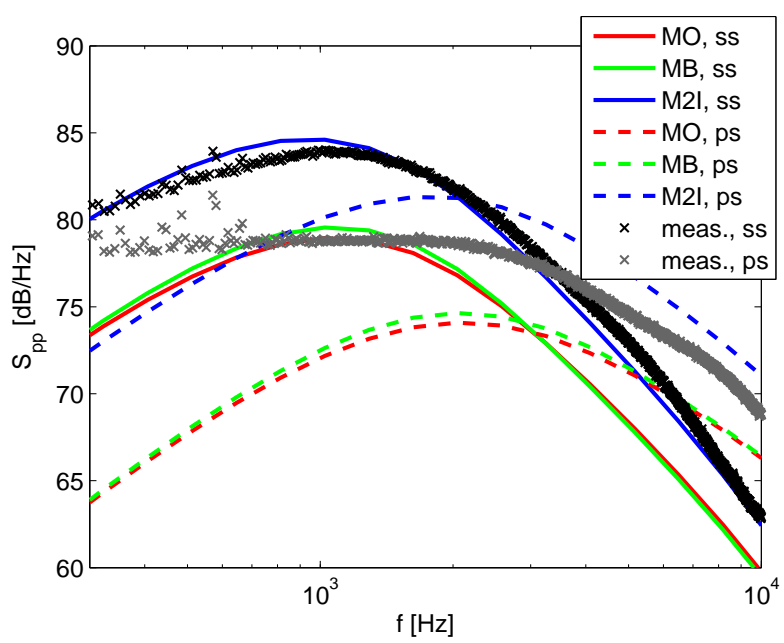

Figure 7. Surface pressure computations compared to the BANC III measurements, case 2.

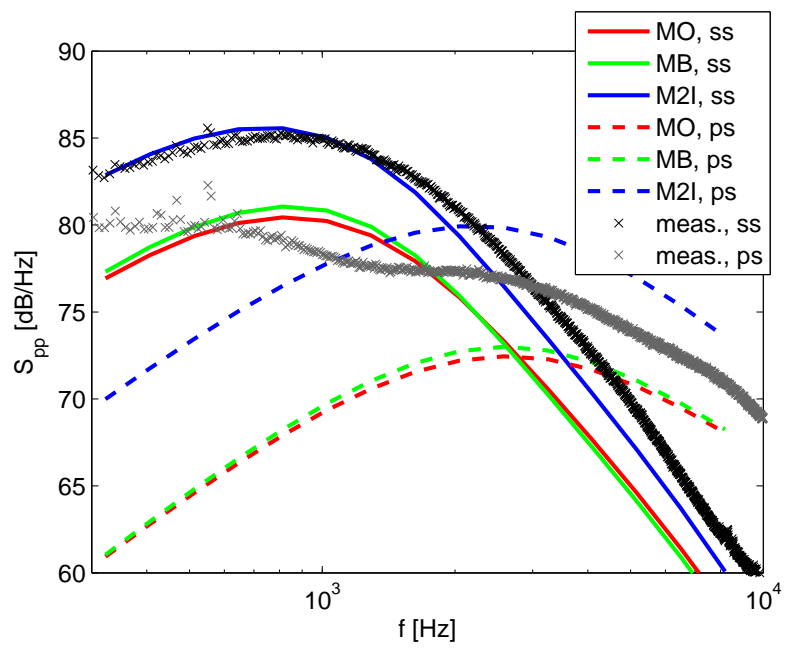

Figure 8. Surface pressure computations compared to the BANC III measurements, case 3.

suction side, but not on the pressure side. Hence, it is not ensured that the input values for the pressure side are correct. Transition of the boundary layer was fixed at $\mathrm{x} / \mathrm{c}=0.065$ which ensures that it happens far upstream of the TE and normally decreases the uncertainty of the predictions of the turbulence quantities. On the suction side there is a pressure rise along most parts of the boundary layer. On the pressure side there is usually a pressure drop downstream of the leading edge. Towards the trailing edge the pressure gradient goes towards zero. Therefore the development of the turbulence structures in the boundary layer might be very different when compared between pressure and suction side. The turbulence model used in CFD is usually validated for zero pressure gradient boundary layer flow. 


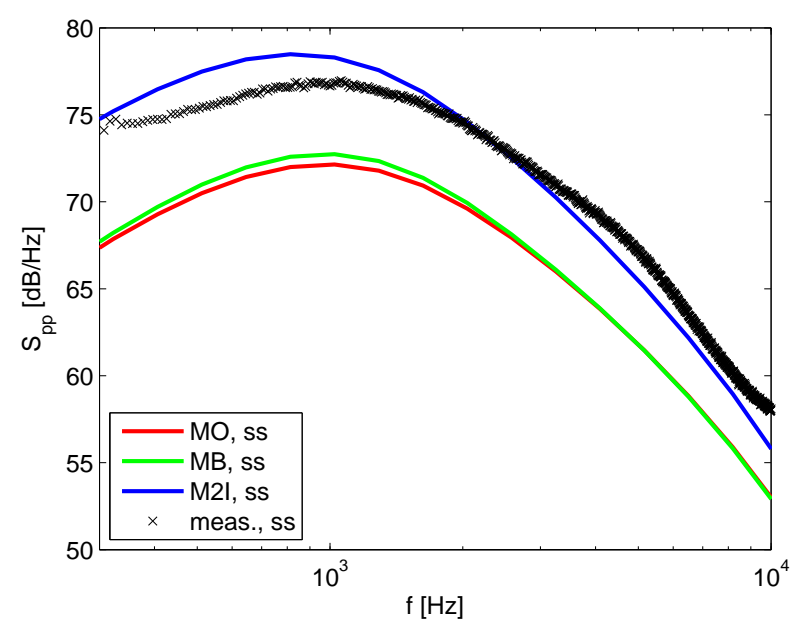

Figure 9. Surface pressure computations compared to the BANC III measurements, case 4.

\subsection{Evaluation of the Far Field Sound Pressure Predictions}

Figures 10, 11, 12 and 13 show the comparison of the predicted far field sound pressure spectra with the measurements of the BANC III database, case 1 to 4 . The

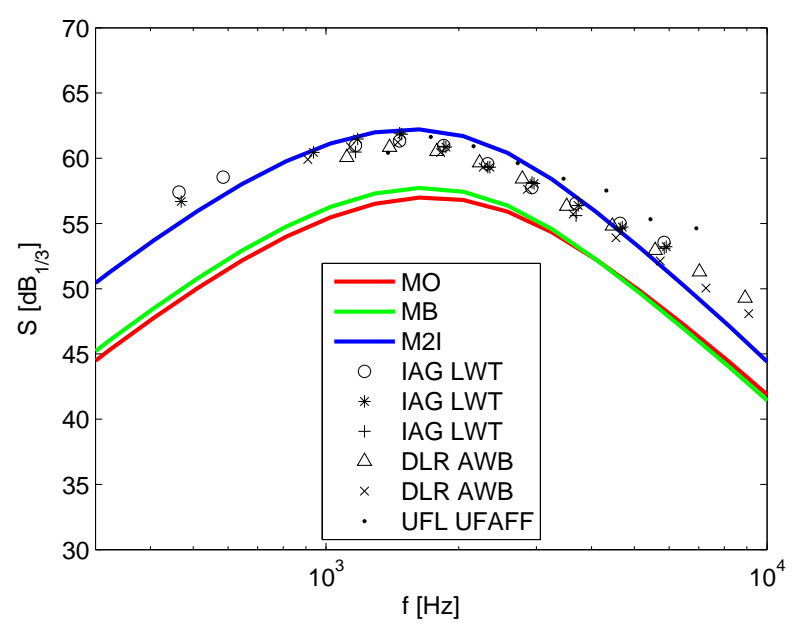

Figure 10. Far field sound pressure computations compared to the BANC III measurements, case 1.

predictions of the M2I model are in good agreement with the measurements. Difference can be observed for the asymmetric cases 2 and 3, figure 11 and 12. The differences originate mainly from the overprediction of the pressure side contribution. Figure 14 and 15 show how the contributions from pressure and suction side add up to the overall sound pressure level. Especially in case 3 the pressure side gives a contribution in the high frequency range which is considerably above the measured levels. The surface pressure level was overestimated in this case as well, figure 8 . Hence, the overestimation of the far field sound pressure level in this

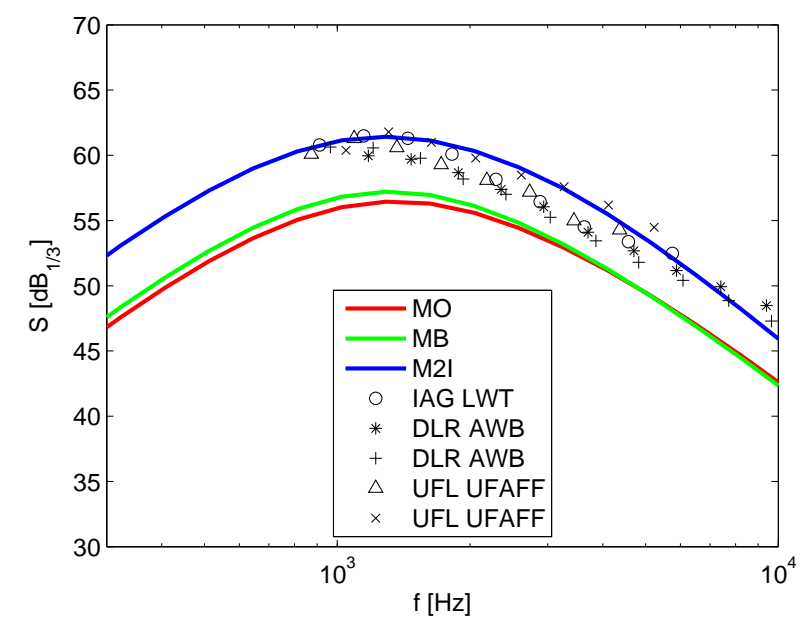

Figure 11. Far field sound pressure computations compared to the BANC III measurements, case 2.

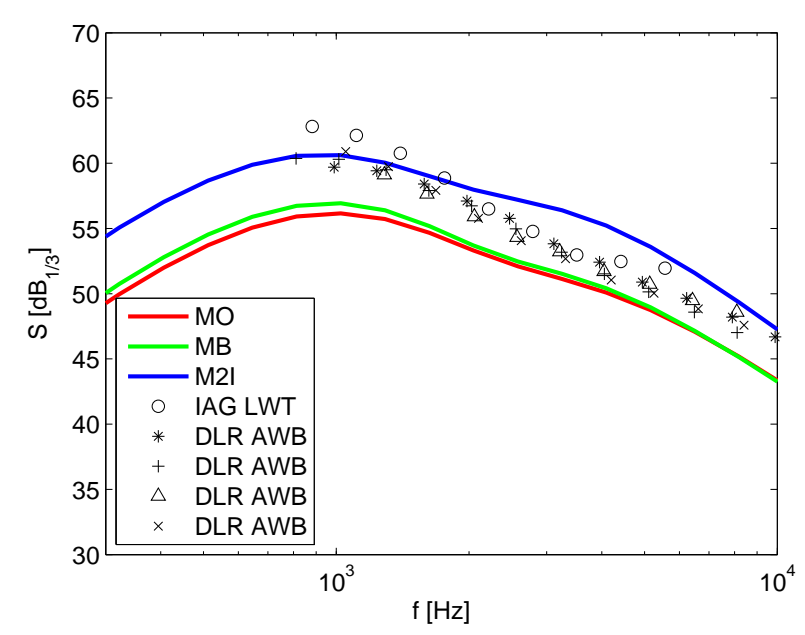

Figure 12. Far field sound pressure computations compared to the BANC III measurements, case 3.

frequency is an inherited error. In case 4 the M2I model underestimates the far field sound pressure level in the high frequency range. This might indicate that there is an effect of the Reynolds number on the length scale $\Lambda$. The surface pressure prediction shows the same tendency, figure 9 , but the effect is much less severe.

The models MO and MB which are based on the Blake assumption, eq. 5 , give very similar results. The anisotropy parameters $\beta_{1}, \beta_{2}$ and $\beta_{3}$ have a very small effect on the result with the present tuning. The frequency dependent length scale $\mathrm{L}_{2}^{22}$ of the $\mathrm{MB}$ model changes the spectral shape of the far field sound only marginally compared to the $\mathrm{MO}$ model with fixed integral length scale $\Lambda_{2}^{22}$. The spectral level is underestimated in all 4 cases. The spectral shape of the far field sound pressure coincides more or less with the measured one. The far field sound pressure spectrum is less sensitive to errors in modelling the velocity spectra or the 


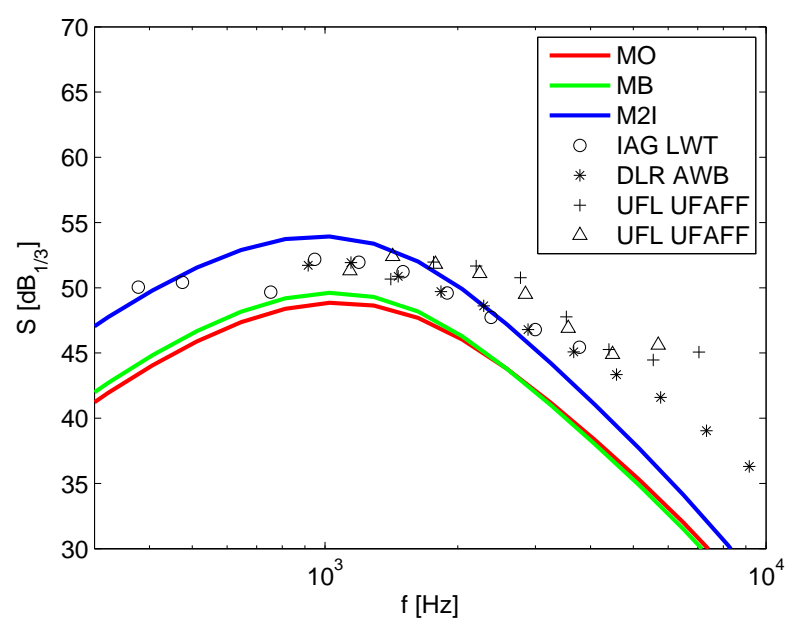

Figure 13. Far field sound pressure computations compared to the BANC III measurements, case 4.

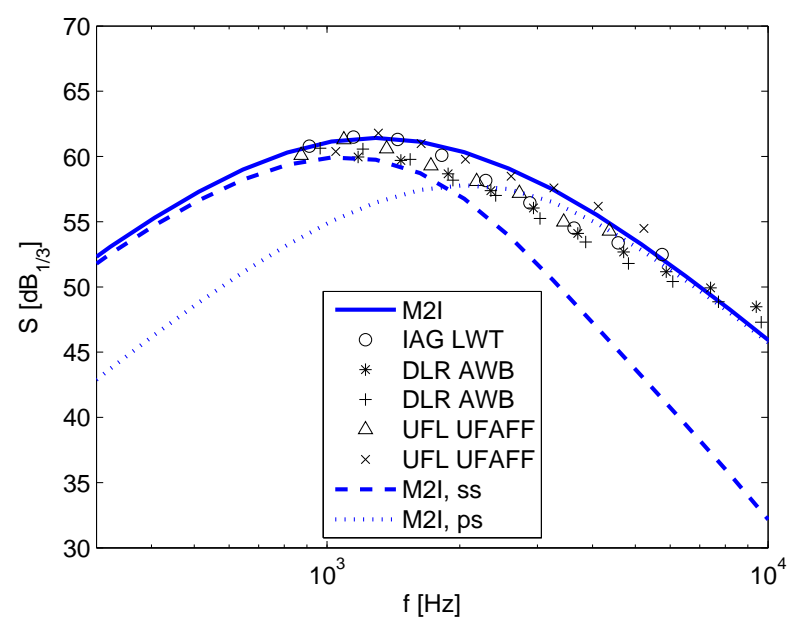

Figure 14. Far field sound pressure contributions from suction and pressure side for BANC III case 2.

vertical correlation than the surface pressure spectrum. The spread of the spectra measured in different facilities is too large for an accurate evaluation of the prediction models.

\section{DISCUSSION AND CONCLUSIONS}

A new model to predict the turbulent boundary layer trailing edge noise of an aerofoil section based on the theory of Kraichnan [13] and Howe [16] was developed. The model is similar to the well known TNO model [3]. The main difference is that this model does not rely on the assumption by Blake [14] to model the surface pressure frequency wave number spectrum. Blake assumed that the boundary layer can be divided up into thin layers and that within a layer the distribution of the spectral energy of the vertical velocity can be assumed equal to the product of the auto spectrum and the vertical correlation length scale. This is true if the vertical correlation length scale is very small compared to

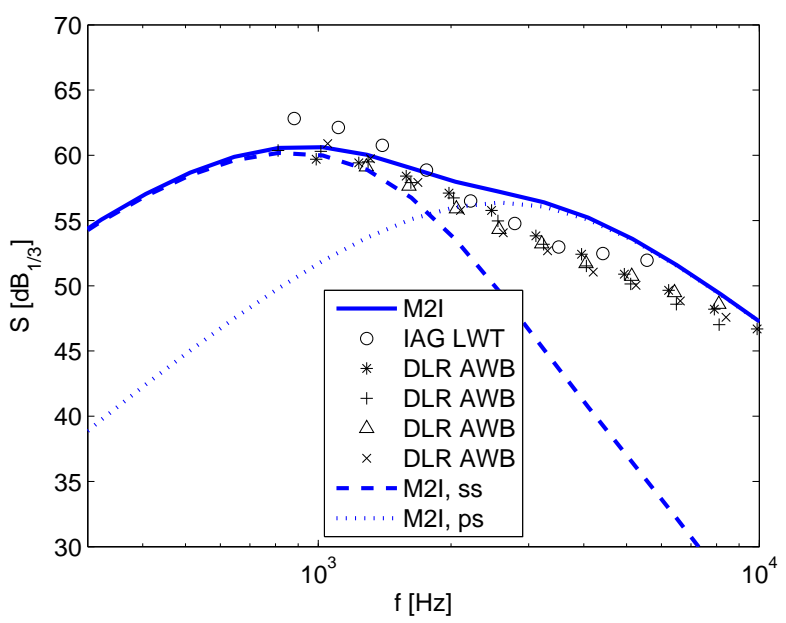

Figure 15. Far field sound pressure contributions from suction and pressure side for BANC III case 3.

the boundary layer thickness.

In order to avoid making Blake's assumption a model for the cross correlation function for the vertical velocity had to be developed and applied in Kraichnan's formula for the surface pressure frequency wave number spectrum. It was shown that this model gave much better predictions of the surface pressure and the far field sound pressure than models relying on Blake's assumption, if the vertical velocity spectrum was correctly modelled.

The new model gave excellent results for the surface pressure on the suction side of the NACA0012 aerofoil and the BANC III test case conditions. The length scale and turbulence parameters computed with CFD were verified by the comparison with measurements in this cases. On the pressure side those parameters were not verified by measurements and the model overestimated the surface pressure. The flow conditions on the pressure side are very different from the ones on the suction side. They might have an influence on the boundary layer turbulence and alter the length scale and spectral parameters. This might explain the overprediction. A detailed investigation of the boundary layer turbulence on the pressure side is recommended. The prediction of the far field sound pressure coincided with the measurements in the low frequency range where the overall level was dominated by the suction side contribution. In the high frequency range where the overall level was dominated by the pressure side there was consequently an overprediction.

\section{REFERENCES}

[1] M. Roger and S. Moreau. Back-scattering correction and further extensions of Amiet's trailing-edge noise model. Part 1: theory. J. Sound Vib., 286:477-506, 2005.

[2] S. Oerlemans, P. Sijtsma, and B. Mendes Lopez. Localization and Quantification of Noise Sources on a Wind Turbine. J. Sound Vib., 299:869-883, 2007. 
[3] R. Parchen. Progress report DRAW: A Prediction Scheme for Trailing-Edge Noise Based on Detailed Boundary-Layer Characteristics. TNO Rept. HAGRPT-980023, TNO Institute of Applied Physics, The Netherlands, 1998.

[4] P. Moriarty, G. Guidati, and P. Migliore. Prediction of Turbulent Inflow and Trailing-Edge Noise for Wind Turbines. In Proc. of the $11^{\text {th }}$ AIAA/CEAS Aeroacoustics Conf., AIAA Paper 2005-2881, Monterey, CA, 2005.

[5] T. Lutz, A. Herrig, W. Würz, M. Kamruzzaman, and E. Krämer. Design and Wind-Tunnel Verification of Low-Noise Airfoils for Wind Turbines. AIAA Journal, 45(4):779-785, 2007.

[6] M. Kamruzzaman, T. Lutz, A. Herrig, and E. Krämer. Semi-empirical modeling of turbulent anisotropy for airfoil self noise predictions. AIAA Journal, 50(1):4660, January 2012.

[7] Franck Bertagnolio, Andreas Fischer, and Wei Jun Zhu. Tuning of turbulent boundary layer anisotropy for improved surface pressure and trailing-edge noise modeling. Journal of Sound and Vibration, 333(3):9911010, 2014.

[8] A. Fischer. Experimental characterization of airfoil boundary layers for improvement of aeroacoustic and aerodynamic modeling. $\mathrm{PhD}$ thesis, Technical University of Denmark, 2012.

[9] M. Kamruzzaman, Th. Lutz, W. Würz, Wen Zhong Shen, Wei Jun Zhu, Martin Otto Laver Hansen, Franck Bertagnolio, and Helge Aagaard Madsen. Validations and improvements of airfoil trailing-edge noise prediction models using detailed experimental data. Wind Energy, 15(1):45-61, 2012.

[10] Oksana Stalnov, Paruchuri Chaitanya, and Phillip F. Joseph. On the measurement and prediction of windturbine trailing-edge noise. In Proceedings of the 6th International Conference on Wind Turbine Noise, Glasgow, UK, 2015.

[11] S. Remmler, J. Christophe, J. Anthoine, and S. Moreau. Computation of wall-pressure spectra from steady flow data for noise prediction. AIAA Journal, 48(9):19972007, 2010.

[12] Y. Rozenberg, M. Roger, and S. Moreau. Rotating blade trailing-edge noise : experimental validation of analytical model. AIAA Journal, 48:951-962, 2010.

[13] R.H. Kraichnan. Pressure Fluctuations in Turbulent Flow over a Flat Plate. J. Acoust. Soc. Am., 28(3):378390, 1956.

[14] W. K. Blake. Mechanics of Flow-Induced Sound and Vibration, Vol.I and II, volume in Applied Mathematics and Mechanics. Frenkiel, F.N. and Temple, G. (eds.), Academic Press, 1986.

[15] M. Drela. Low Reynolds Number Aerodynamics, volume 54, chapter XFOIL: An Analysis and Design
System for Low Reynolds Number Airfoils, pages 112. Mueller, T.J. (ed.), Lecture Notes in Engineering, Springer-Verlag, Berlin, 1989.

[16] M. S. Howe. A Review of the Theory of Trailing Edge Noise. J. Sound Vib., 61(3):437-465, 1978.

[17] D.M. Chase. Sound Radiated by Turbulent Flow off a Rigid Half-Plane as Obtained from a Wavevector Spectrum of Hydrodynamic Pressure. J. Acoust. Soc. Am., 52:1011-1023, 1972.

[18] K.L. Chandiramani. Diffraction of Evanescent Waves with Applications to Aerodynamically Scattered Sound and Radiation from Unbaffled Plates. J. Acoust. Soc. Am., 55(1):19-29, 1974.

[19] R. K. Amiet. Noise due to Turbulent Flow Past a Trailing Edge. J. Sound Vib., 47(3):387-393, 1976.

[20] F. Bertagnolio. Trailing Edge Noise Model Applied to Wind Turbine Airfoils. Tech. Rep. Ris $\varnothing-\mathrm{R}-1633(\mathrm{EN})$, Ris $\varnothing$-DTU, Roskilde, Denmark, January 2008.

[21] T. F. Brooks and T. H. Hodgson. Trailing Edge Noise Prediction from Measured Surface Pressures. J. Sound Vib., 78(1):69-117, 1981.

[22] T. v. Karman. Progress in the statistical theory of turbulence. Proc. Nat. Akad. Sci., 34:530-539, 1948.

[23] F. Bertagnolio. Boundary Layer Measurements of the NACA0015 and Implications for Noise Modeling. Tech. Rep. Ris $\varnothing-R-1761(E N)$, Ris $\varnothing-D T U$, Roskilde, Denmark, January 2011.

[24] P. Lysak and T. Brungart. Velocity spectrum model for turbulence ingestion noise from computational-fluiddynamics calculation. AIAA Journal, 41(9):1827-1829, 2003.

[25] J. Mann. The spatial structure of neutral atmospheric surface-layer turbulence. J. of Fluid Mech., 273:141168, 1994.

[26] R.L. Panton and J.H. Linebarger. Wall pressure spectra calculations for equilibrium boundary layers. J. Fluid Mech., 65(2):261-287, 1974.

[27] M. Herr, R. Ewert, C. Rautmann, M. Kamruzzaman, D. Bekiropoulos, R. Arina, A. Iob, P. Batten, S. Chakravarthy, and F. Bertagnolio. Broadband trailingedge noise predictions - overview of banc-iii results. In Proc. of the $21^{\text {st }}$ AIAA/CEAS Aeroacoustics Conf., AIAA Paper 2015-2847, Dallas, TX, USA, 2015.

[28] N. N. Sørensen. General Purpose Flow Solver Applied to Flow over Hills. Ris $\varnothing-\mathrm{R}-827-(\mathrm{EN})$, Ris $\varnothing$ National Laboratory, Roskilde, Denmark, June 1995.

[29] J. A. Michelsen. Basis3D - A Platform for Development of Multiblock PDE Solvers. Tech. Rep. AFM 92-05, Technical University of Denmark, 1992.

[30] J. A. Michelsen. Block Structured Multigrid Solution of 2D and 3D Elliptic PDE's. Tech. Rep. AFM 94-06, Technical University of Denmark, 1994. 